\title{
The relationship between physical activity levels and health-related quality of life in elderly individuals aged 65 years and above with a chronic disease
}

\author{
Authors' Contribution: \\ A Study Design \\ B Data Collection \\ C Statistical Analysis \\ D Data Interpretation \\ E Manuscript Preparation \\ F Literature Search \\ G Funds Collection \\ Nevzat Demirci ${ }^{1}$ ABCEF, Pervin Toptaş Demirci ${ }^{2}$ ADEF, Oktay Zırhlı 3 ACDEF \\ ${ }^{1}$ Faculty of Sports Science, Mersin University, Mersin, Turkey \\ ${ }^{2}$ Mersin University Vocational School of Erdemli, Mersin, Turkey \\ ${ }^{3}$ Department of Physical Education and Sports, Mersin University, Mersin, Turkey
}

\section{abstract}

Background: Chronic diseases are the leading cause of death worldwide with increasing prevalence in the population aged 65 years and above. This study aimed to evaluate the relationship between physical activity level and health-related quality of life in elderly individuals.

Material and methods:

The participants aged 65 years and older (46 males and 35 females) were divided into 3 groups according to their physical activity levels: low physical activity $(<150$ minutes/week), moderate physical activity (150-300 minutes/week) and high physical activity level (> 300 minutes/week). Health-related quality of life (HRQoL) was calculated using EQ-5D scale. Spearman's correlation coefficient was used to determine the relationship between physical activity level and HRQoL scores in elderly individuals.

Results: A significant relationship and differences were found between high, moderate and low physical activity levels and HQQoL dimensions $(\mathrm{P}<0.05)$. The moderate and high physical activity groups were found to be significantly higher in all dimensions compared to the low physical activity group according to HRQoL scores $(P<0.001)$.

Conclusions: It has been concluded that high and moderate physical activity levels have a great positive relationship with HRQoL in individuals aged 65 years and older with a chronic disease.

Key words: elderly individuals, physical activity, chronic disease, HRQoL, immune function.

\section{article details}

Article statistics: Word count: 4,813; Tables: 4; Figures: 1; References: 39

Received: March 2019; Accepted: May 2020; Published: September 2020

Full-text PDF: http://www.balticsportscience.com

Copyright

Indexation:

(c) Gdansk University of Physical Education and Sport, Poland

Celdes, Clarivate Analytics Emerging Sources Citation Index (ESCI), CNKI Scholar (China National Knowledge Infrastructure), CNPIEC, De Gruyter - IBR (International Bibliography of Reviews of Scholarly Literature in the Humanities and Social Sciences), De Gruyter - IBZ (International Bibliography of Periodical Literature in the Humanities and Social Sciences), DOAJ, EBSCO - Central \& Eastern European Academic Source, EBSCO - SPORTDiscus, EBSCO Discovery Service, Google Scholar, Index Copernicus, J-Gate, Naviga (Softweco, Primo Central (ExLibris), ProQuest - Family Health, ProQuest - Health \& Medical Complete, ProQuest - Illustrata: Health Sciences, ProQuest - Nursing \& Allied Health Source, Summon (Serials Solutions/ProQuest, TDOne (TDNet), Ulrich's Periodicals Directory/ulrichsweb, WorldCat (OCLC)

Funding: This research received no specific grant from any funding agency in the public, commercial, or not-for-profit sectors.

Conflict of interests: Corresponding author: Authors have declared that no competing interest exists.

Nevzat Demirci, PT, PhD, Mersin University Faculty of Sports Science, Mersin/ Türkey, e-mail: nevzatdemirci44@ hotmail.com https://orcid.org/0000-0001-8442-270X

Open Access License:

This is an open access article distributed under the terms of the Creative Commons Attribution-Non-Commercial-NoDerivatives 4.0 International (https://creativecommons.org/licenses/by-nc-nd/4.0/), which permits use, distribution and reproduction in any medium, provided the original work is properly cited, the use is non-commercial and is otherwise in compliance with the license. 


\section{INTRODUCTION}

Aging is increasing rapidly worldwide, and chronic diseases are the leading cause of death worldwide with increasing prevalence at age 65 and above. On the other hand, increased physical activity (PA) and exercise are associated with a reduced risk of chronic diseases [1, 2]. PA and health-related quality of life (HRQoL) are important factors for optimal health in the elderly. Examining the relationship between PA and HRQoL becomes more important as the number of seniors worldwide is increasing [3,4]. Aging is a chronic condition of the human life cycle, accompanied by conditions such as cardiovascular disease, hypertension, diabetes mellitus, cancer and/or mental illness [5].

A chronic disease is the result of a non-contagious, often prolonged, slow progress and typically genetic, environmental, or poor lifestyle [2]. Although life expectancy estimates have steadily increased over the past two centuries, current estimates support a potential drop in life expectancy for future generations due to the increase in various chronic diseases such as low respiratory disease, obesity, cancer, cardiovascular disease (CVD) [6, 7]. The literature today supports the inclusion of daily PA and exercise in the lifestyle to provide a tool for the prevention of primary diseases while reducing the risk of chronic diseases and mortality [8]. Although changing disease risk factors reduces the overall risk of a chronic disease, modifiable risk factors such as sedentary behavior are associated with an increased risk for a chronic disease $[9,10]$. Changeable risk factors are positively affected by lifestyle such as daily PA, regular exercise, healthy eating, social participation, spirituality and stress management. PA and regular exercise positively affect risk factors for chronic diseases such as CVD, type 2 diabetes, obesity and cancer [11, 12].

Both cross-sectional and longitudinal studies in humans have shown the profound effect of exercise on the immune system. PA and mid-intensity exercise workouts have been shown to improve immune responses to vaccination, reduce chronic low-grade inflammation and improve various immune markers in various disease states such as cancer, HIV, cardiovascular disease, diabetes, cognitive impairment and obesity [13-16]. However, it is suggested that regular shortterm (i.e. up to 45 minutes) medium-intensity PA and exercises are immunoenhancer $[17,18]$. Health related quality of life (HRQoL) is a criterion that includes various concepts and covers physical, mental and social health dimensions [19]. Moreover, as the age and chronic conditions of the population increase, there is a need to encourage behavior that can prevent disability and hospitalization. Physical activity (PA) has well-documented beneficial effects on the prevention and treatment of noncommunicable diseases (NCDs) and other chronic conditions [20] and the support of HRQoL [21, 22].

Physical activity appears to be associated with improving functional performance and HRQoL [23, 24]. Physical activity can help maintain or sustain aging people's health. Regular physical exercise can lead to high HRQoL levels in the elderly aged 65 and over. It may also proportionately assist elderly people to inhibit a decrease in HRQoL and enhance their enjoyment of life [12, 25]. Therefore, the increase in PA among older people has become an international priority. This priority overlaps with the fact that the number of the elderly is increasing worldwide, and the proportion of people over 65 is growing faster than other age groups. This means that society should rethink how to look after the elderly to maximize the health and functional capacity of the elderly, because physical activity plays an important role in enhancing health-related quality of life (HRQoL) 
among the elderly and improves aging health [3]. The increasing interest in the relationship between PA and HRQoL in the elderly people aged 65 and over in recent years has shown that a moderate PA level has a positive effect on daily life activities and emphasizes the importance of physical life in the elderly. It is also important to incorporate physical activity into the life of older adults as a means of improving their quality of life. Therefore, this study was conducted to evaluate the relationship between physical activity level and health-related quality of life, and to examine whether physical activity level has any effect on HRQoL dimensions.

\section{MATERIAL AND METHODS}

\section{PARTICIPANTS}

This (cross-sectional) study was conducted between March and July 2019 in patients aged 65 and over (46 males, 35 females) with a chronic disease in State Hospital polyclinics in Ankara. All participants walked independently [3]. Subjects were excluded from the study if they could not walk for at least 6 minutes without orthopedic limitations, cognitive impairments or any help. The participants were divided into 3 groups according to their weekly walking time: low physical activity (walking duration $<150$ minutes/week), moderate physical activity (walking duration 150-300 minutes/week), high physical activity (walking duration $>300$ minutes/week). Participants were asked to report how many minutes they walked a week $[3,12]$.

This study was approved by the Mersin University Ethics Research Board according to Helsinki principles. Each participant was informed about the objectives and procedure of the study and signed written informed consent before starting the study. The flow diagram showing the subjects aged 65 years and above participating in the study is shown in Fig. 1.

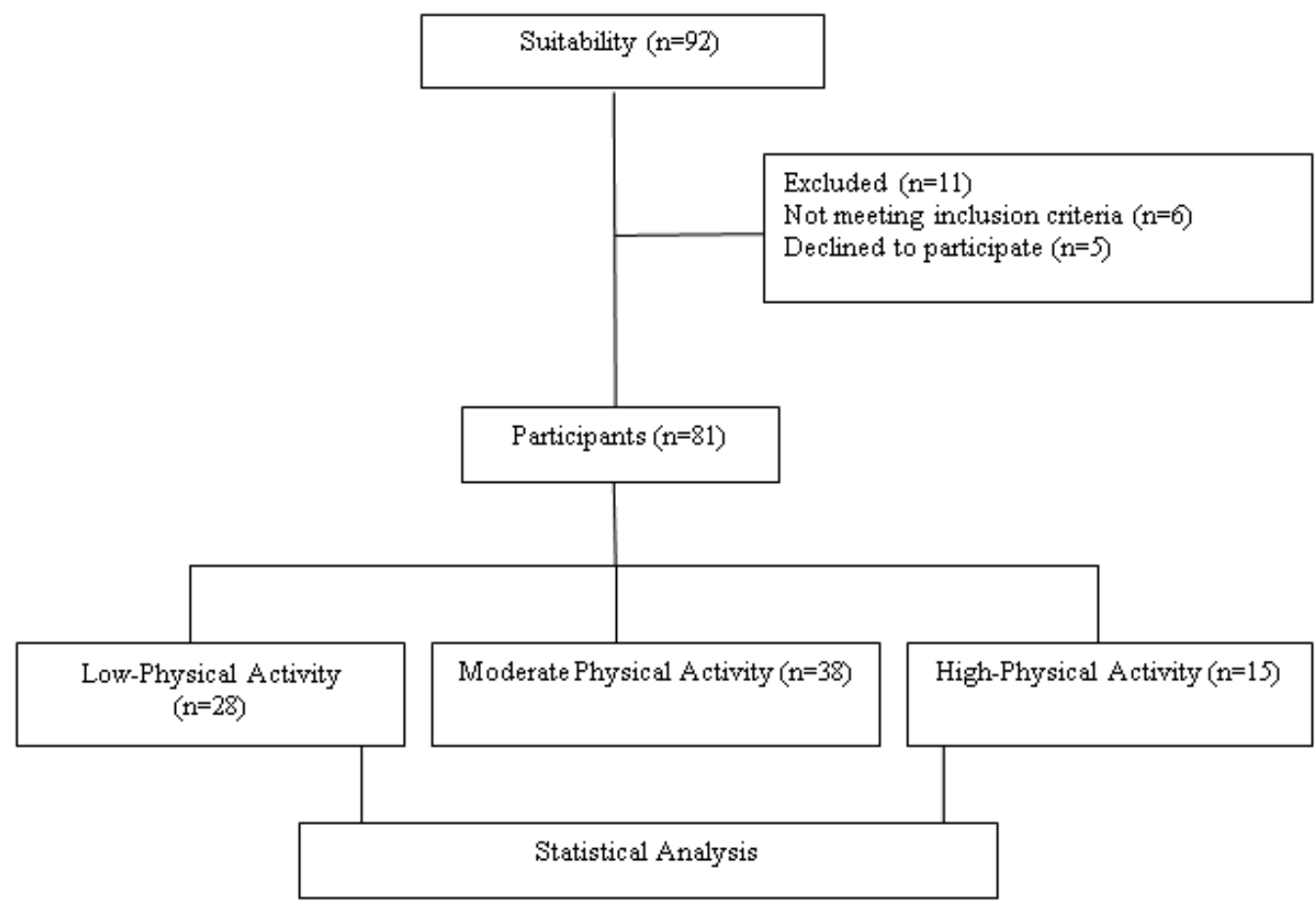

Fig. 1. Flow showing the selection of adults aged 65 years and above to participate in the study 


\section{DATA COLLECTION TOOLS}

Evaluation procedures were carried out using two scales. Physical activity was evaluated using the physical activity socio-cultural adapted questionnaire (PASCAQ), whereas HRQoL was assessed using the Euro-Qol-5 dimensions-3 levels scale (EQ-5D-3L). In addition, measurement of participants' daily living activities (DLA) was provided. All participants were interviewed for 10 minutes personally, and scale forms were filled and collected by the researcher. The following basic clinical features were included: age, gender, medical history, medications, motor or sensory dysfunctions. In addition, BMI $=$ Body Weight (kg) / Height2 (m) was obtained to calculate the body mass index (BMI).

\section{MEASURE OF ACTIVITIES OF DAILY LIVING (ADL)}

The Katz index was used to evaluate personal ADL [26].The index has been defined as a valid and reliable measure to determine the level of independence in performing ADL [27]. Evaluation is based on the ability to perform an activity without the help of another person. The Katz ADL index includes six basic activities of daily life (BADL): bathing, dressing, toileting, transferring, continuity and nutrition. The ability to perform each activity was assessed using a two-point categorical scale: $1=$ independence and $0=$ dependency. The total score ranges from 0 (low function, dependent) to 6 (high function, independent).

\section{PHYSICAL ACTIVITY MEASURE}

Physical activity socio-cultural adapted questionnaire (PA-SCAQ) was applied to measure the level of physical activity for each participant. PA-SCAQ included the following questions: How do you walk? How long is the walking time? What are your home activities (such as walking or gardening)? The structure of the survey on physical activity areas considered the duration and frequency according to the recommendations of the World Health Organization (WHO), taking into account some suitable variables of physical activity measures for elderly individuals. Based on the WHO recommendations, physical activity variables are classified as walking, home activities and outdoor activities. In order to calculate the duration and frequency of the activities, the time spent per week (minutes/week) on these activities was discussed. The participants were divided into 3 levels of physical activity based on their activity times throughout the week: low physical activity ( $<150$ minutes/week), moderate physical activity (150-300 minutes/week) and high physical activity (>300 minutes/week) [28].

\section{HRQOL (EQ-5D) GENERAL QUALITY OF LIFE SCALE}

EQ-5D is a general health scale used to measure the quality of life. The EQ5D scale consists of five dimensions: mobility, self-care, usual activities, pain/ discomfort, and anxiety/depression. Answers to each dimension were as follows: there are no problems, there are some problems, and there are 3 options as a major problem. In the score function, 0 indicates death, 1 indicates perfect health, while negative values are unconscious, living dependent on the bed, etc. Quality of life scores ranging from 0 to 100 are obtained from the scale $[29,30]$. 


\section{STATISTICAL ANALYSIS}

All statistical analyses were performed with SPSS 22.0 version (SPSS, Inc. Chicago, Illinois, USA). The normality of the dependent variable's data was screened using the Shapiro-Wilks test. In the analysis of the data obtained in the research, frequency, arithmetic mean, standard deviation, Spearman correlation and Mann-Whitney U Test were used to measure the strength and direction of the relationship between physical activity and HRQoL (EQ-5D).

Kruskal-Wallis tests were applied to the ordinal variables of the physical activity groups to determine changes between the 3 groups according to each group variable including BMI, and the medical diagnosis. Spearman correlation coefficient was used to measure the strength and direction of the relationship between physical activity and HRQoL including all subjects in the 3 groups. Significance was accepted as $\mathrm{p}<0.05$.

\section{RESULTS}

81 elderly individuals aged 65 years and above with a chronic disease (46 males and 35 females) participated in this study. Their mean age was (72.1 \pm 5.4 years old), height (168 $\pm 4.6 \mathrm{~cm})$, weight $(78.3 \pm 6.2 \mathrm{~kg})$, and the mean body mass index (BMI) was $(27.6 \pm 2.1)$. $74.1 \%$ of the participants were diagnosed clinically with a chronic disease, such as diabetes mellitus (30\%), hypertension (43.3\%), cardiovascular disease (26.7\%). About 51.9\% the elderly individuals with a chronic disease aged over 65 years were smokers and $48.1 \%$ were nonsmokers. Sleep quality was good in $64.2 \%$ of the subjects and bad in $35.8 \%$ of them. Walking duration was less than $150 \mathrm{~min} /$ week in $34.5 \%$ of the subjects, between $150-300 \mathrm{~min} /$ week in $47.0 \%$ of the subjects and more than $300 \mathrm{~min} /$ week in $18.5 \%$ of them. Clinical characteristics of all participants aged 65 years and above are demonstrated in Table 1.

Table 1. Demographic and clinical characteristics of all participants aged 65 years and above with a chronic disease

\begin{tabular}{|c|c|}
\hline Variables & $n(\%)$ \\
\hline \multicolumn{2}{|l|}{ Sex } \\
\hline Male (\%) & $46(56.8)$ \\
\hline Females (\%) & $35(43.2)$ \\
\hline Age $(X \pm S D)$ & $72.1 \pm 5.4$ \\
\hline Height $(\mathrm{cm})(\mathrm{X} \pm \mathrm{SD})$ & $168 \pm 4.6$ \\
\hline 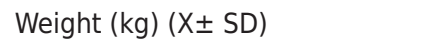 & $78.3 \pm 6.2$ \\
\hline $\mathrm{BMI}(\mathrm{kg} / \mathrm{m} 2)(\mathrm{X} \pm \mathrm{SD})$ & $27.6 \pm 2.1$ \\
\hline \multicolumn{2}{|l|}{ Diagnosis of Chronic Diseases } \\
\hline Yes/No n (\%) & $60(74.1) / 21(25.9)$ \\
\hline Diabetes Mellitus & $18(30)$ \\
\hline Hypertension & $26(43.3)$ \\
\hline Cardiovascular & $16(26.7)$ \\
\hline Smoking Habits (yes/no) & $42(51.9) / 39(48.1)$ \\
\hline Sleep Quality (good/bad) & $52(64.2) / 29(35.8)$ \\
\hline \multicolumn{2}{|l|}{ Walking Duration n (\%) } \\
\hline Less than 150 (min/week) & $28(34.5)$ \\
\hline between 150 - 300 (min/week) & $38(47)$ \\
\hline More than 300 (min/week) & $15(18.5)$ \\
\hline
\end{tabular}

$\mathrm{BMI}=$ body mass index, $\mathrm{n}=$ number, $\mathrm{SD}=$ standard deviation. 
As described in Table 2, body mass index (BMI) measures showed higher values in the low-physical activity group than in the moderate physical activity high-physical activity ones $(30.4,28.2$, and 24.2 , respectively). The outcome measures showed that a chronic disease incidence was higher in the moderatephysical activity group than in the low physical activity group and the highphysical activity one $(68.4 \%, 70 \%$, and $22 \%$ respectively). In addition, the number of smokers was higher in the moderate physical activity group (65.8\%) when compared with the low-physical activity group (60.7\%) and the highphysical activity group (53.3\%), as presented in Table 2.

Table 2. Physical activity levels of all participants aged 65 years and above with a chronic disease

\begin{tabular}{|c|c|c|c|c|}
\hline Variables & $\begin{array}{l}\text { Low physical } \\
\text { activity }(n=28)\end{array}$ & $\begin{array}{c}\text { Moderate } \\
\text { physical activity } \\
(\mathrm{n}=38)\end{array}$ & $\begin{array}{l}\text { High physical } \\
\text { activity }(n=15)\end{array}$ & $\mathrm{p}$-value \\
\hline Male (\%) & 18(39.2) & $20(43.5)$ & $8(17.3)$ & .012 \\
\hline Females (\%) & $10(28.6)$ & $18(51.4)$ & $7(20)$ & .013 \\
\hline BMI $\left(\mathrm{kg} / \mathrm{m}^{2}\right)(\mathrm{X} \pm \mathrm{SD})$ & $30.4 \pm 2.6$ & $28.2 \pm 2.9$ & $24.2 \pm 2.3$ & $<.001$ \\
\hline Chronic Diseases n (\%) & $22(78.6)$ & $26(68.4)$ & $12(80)$ & .018 \\
\hline Diabetes Mellitus n (\%) & $6(21.4)$ & $8(21.1)$ & $4(26.6)$ & $<.001$ \\
\hline Hypertension n (\%) & $11(39.3)$ & $10(26.2)$ & $5(33.4)$ & $<.001$ \\
\hline Cardiovascular Disease n (\%) & $5(17.9)$ & $8(21.1)$ & $3(20)$ & $<.001$ \\
\hline Smoking Habits (yes/no) & $17(60.7) / 11(39.3)$ & $25(65.8) / 13(34.2)$ & $8(53.3) / 7(46.4)$ & $<.001$ \\
\hline
\end{tabular}

A significance level of $\mathrm{P}<.05$; $\mathrm{BMI}=$ body mass index, $\mathrm{n}=$ number, $\mathrm{SD}=$ standard deviation

Results of HRQoL measures showed that the group of low-physical activity level recorded walking problems ranging from slight/moderate to severe/ extreme level as $71 \%, 57 \%, 64 \%, 71 \%, 79 \%$ of the participants in the mobility, self-care, usual activities, pain/discomfort, and anxiety/depression dimensions respectively. While the group of moderate physical activity level suffered from walking problems starting from a slight/moderate to severe/extreme level as $45 \%, 47 \%, 42 \%, 71 \%, 58 \%$, and the group of high physical activity level recorded waking problems only in slight/ moderate level as $47 \%, 40 \%, 40 \%$, $67 \%, 53 \%$ of the older adults in the 5 dimensions respectively. No participant suffered from any severe/extreme walking problems in all dimensions in the high-physical activity group. Using Kruskal-Wallis tests, the results showed statistically significant differences between the 3 groups: high, moderate, and low-physical activity groups $(\mathrm{P}<.001)$. Moderate and high physical activity groups showed higher HRQoL scores than the low-physical activity group in all 5 dimensions. In the EQ-VAS measure, the high-level group showed higher scores than the moderate level group and the low-level group $(\mathrm{P}<.001)$ as illustrated in Table 3.

A strong positive correlation was also recorded between the five dimensions of HRQoL and the level of PA in terms of walking minutes. This strong positive correlation means that higher physical activity level goes with high HRQoL scores (and vice versa) as demonstrated in Table 4. 
Baltic Journal of Health and Physical Activity 2020; 12 (3): 103-113

Journal of Gdansk University of Physical Education and Sport

e-ISSN 2080-9999

Table 3. Physical activity levels of all participants aged 65 years and above with a chronic disease

\begin{tabular}{|c|c|c|c|c|}
\hline HRQoL Variables & $\begin{array}{l}\text { Low physical } \\
\text { activity }(n=28)\end{array}$ & $\begin{array}{c}\text { Moderate } \\
\text { physical activity } \\
(n=38)\end{array}$ & $\begin{array}{l}\text { High physical } \\
\text { activity }(n=15)\end{array}$ & $\mathrm{p}$-value \\
\hline \multicolumn{5}{|l|}{ Mobility n (\%) } \\
\hline $\begin{array}{l}\text { I have no problems in walking } \\
\text { about }\end{array}$ & $8(29)$ & $21(55)$ & $8(53)$ & \multirow[t]{3}{*}{$<.001$} \\
\hline $\begin{array}{l}\text { I have slight/moderate } \\
\text { problems in walking about }\end{array}$ & $16(57)$ & $16(42)$ & $7(47)$ & \\
\hline I am unable to walk about & $4(14)$ & $1(3)$ & 0 & \\
\hline \multicolumn{5}{|l|}{ Self-care n (\%) } \\
\hline $\begin{array}{l}\text { I have no problems washing } \\
\text { or dressing myself }\end{array}$ & $12(43)$ & $20(53)$ & $9(60)$ & \multirow[t]{3}{*}{$<.001$} \\
\hline $\begin{array}{l}\text { I have slight/moderate } \\
\text { problems washing or dressing } \\
\text { myself }\end{array}$ & $13(46)$ & $18(47)$ & $6(40)$ & \\
\hline $\begin{array}{l}\text { I am unable to wash or dress } \\
\text { myself }\end{array}$ & $3(11)$ & 0 & 0 & \\
\hline \multicolumn{5}{|l|}{ Usual activities n (\%) } \\
\hline $\begin{array}{l}\text { I have no problems doing my } \\
\text { usual activities }\end{array}$ & $10(36)$ & $22(58)$ & $9(60)$ & \multirow[t]{3}{*}{$<.001$} \\
\hline $\begin{array}{l}\text { I have slight/moderate } \\
\text { problems doing my usual } \\
\text { activities }\end{array}$ & $13(46)$ & $15(39)$ & $6(40)$ & \\
\hline $\begin{array}{l}\text { I am unable to do my usual } \\
\text { activities }\end{array}$ & $5(18)$ & $1(3)$ & 0 & \\
\hline \multicolumn{5}{|l|}{ Pain/discomfort n (\%) } \\
\hline I have no pain or discomfort & $8(29)$ & $11(29)$ & $5(33)$ & \multirow[t]{3}{*}{$<.001$} \\
\hline $\begin{array}{l}\text { I have slight/moderate pain } \\
\text { or discomfort }\end{array}$ & $11(39)$ & $25(66)$ & 10(67) & \\
\hline $\begin{array}{l}\text { I have extreme pain or } \\
\text { discomfort }\end{array}$ & $9(32)$ & $2(5)$ & 0 & \\
\hline \multicolumn{5}{|l|}{ Anxiety/depression n (\%) } \\
\hline $\begin{array}{l}\text { I am not anxious or } \\
\text { depressed }\end{array}$ & $6(21)$ & $16(42)$ & $7(47)$ & \multirow[t]{3}{*}{$<.001$} \\
\hline $\begin{array}{l}\text { I am slightly/moderately } \\
\text { anxious or depressed }\end{array}$ & $14(50)$ & $21(55)$ & $8(53)$ & \\
\hline $\begin{array}{l}\text { I am extremely anxious or } \\
\text { depressed }\end{array}$ & $8(29)$ & $1(3)$ & 0 & \\
\hline EQ-VAS (mean (SD)) & $61 \pm 11.4$ & $69 \pm 12.2$ & $78 \pm 6.7$ & $<.001$ \\
\hline
\end{tabular}

A significance level of $\mathrm{P}<.05$; EQ-VAS=EuroQol-visual analogue scale, HRQoL=health-related quality of life, $\mathrm{n}=$ number, $\mathrm{SD}=$ standard deviation.

Table 4. Relationship between HRQoL dimensions and physical activity levels of participants aged 65 years old and above with a chronic disease

\begin{tabular}{lccc} 
& \multicolumn{3}{c}{ 95\% confidence interval } \\
\cline { 2 - 4 } HRQoL variables & Lower & Upper & rs \\
\hline Mobility scores & 0.71 & 0.42 & 0.62 \\
Self-care scores & 0.59 & 0.36 & 0.56 \\
Usual activity scores & 0.66 & 0.40 & 0.53 \\
Pain/discomfort scores & 0.42 & 0.17 & 0.55 \\
Anxiety/depression scores & 0.48 & 0.21 & 0.39 \\
EQ-VAS score & 0.51 & 0.77 & 0.69 \\
\hline
\end{tabular}

EQ-VAS=EuroQol-visual analogue scale, HRQoL=health-related quality of life, rs: Spearman's correlation coefficient 


\section{DISCUSSION}

This study aimed to evaluate a relationship between the physical activity level and health-related quality of life (HRQoL) in elderly individuals (aged 65 years and above). Due to the physiological and cognitive changes that occur with aging, it is very difficult to determine an exact PA measurement to be used for older people [31]. We used data from PA-SCAQ to determine PA levels. WHO [28] recommends that seniors do moderate physical activity for at least 150 minutes during a week. However, it is recommended to increase the moderate physical activity to 300 minutes per week for additional health benefits. Moderate physical activity is defined as the activity in which large muscles of the body move rhythmically for a long time. For example, walking, running, swimming and cycling [3].

According to our findings, there is a positive relationship between physical activity levels and HRQoL, and physical activity was found to have a significant relationship with the functional and subjective dimensions of HRQoL. This positive relationship suggests that physical activity levels in individuals aged 65 and above can help them achieve desired health benefits. Our results found that $34.5 \%$ of individuals aged 65 years and above constitute the low physical activity group, and the majority of individuals aged 65 years and above have at least 1 diagnosed disease. The elderly individuals with low-physical activity $(<150$ minutes/week) were reported to have more commonly a chronic illness, such as diabetes, hypertension, and cardiovascular disease. On the other hand, the middle-aged, and older adults with high physical activity level (>300 minutes/ week) had higher scores of HRQoL and lower levels of disabilities. Many studies have shown that regular moderate PA, such as walking, has important benefits for health and treatment of a number of diseases [24]. Accordingly, increasing PA among persons aged 65 years and above has become an international priority, so the elderly have been encouraged to participate regularly in moderate intensity activities [32, 33].

In their study, Beitz and Doren [34] suggested that mild sports and walking have positive effects on controlling cardiovascular diseases in post-menopausal women. Also in another study, HRQoL was significantly higher in moderate and high PA groups compared to the low physical activity (PA) group in all dimensions. A significant relationship was determined between the five dimensions of HRQoL and the PA level. In the low PA group, hypertension prevalence (64\%) and diabetes prevalence (50\%) were determined. As a result, a strong relationship was found between higher levels of physical activity and all dimensions of HRQoL [3]. Many studies have shown that regular physical activity exerts a significant improvement in health variables and disease control [3, 12, 30]. Therefore, it can be argued that regular physical activity causes a significant improvement in health variables and disease control, and that individuals aged 65 and above have a strong relationship between all dimensions of HRQoL.

According to our findings, HRQoL levels of the participants with high PA levels were also determined to be high. It was determined that the mobility dimension in the high physical activity group was higher than the low physical activity group rather than the moderate physical activity group. These results support a high relationship between physical activity and HRQoL. Similar results were reported by Abdelbasset and Nambi that higher-physical activity has a better HRQoL than low-physical activity in elderly people [12]. These results are consistent with randomized controlled trials that have shown increases in PA 
with simultaneous increases in HRQoL $[35,36]$. Walking time appears to be directly related to the positive strength of leg muscles and physical capacity in elderly individuals, because walking is the usual physical activity in older adults and can be easily adapted in everyday life without effort [37]. Therefore, it was accepted as an easy and valid measure for elderly quality of life [38]. Therefore, people with high physical activity levels showed high scores in the self-care and usual activity dimensions specified in HRQoL. Therefore, high physical activity supports the reduction of disease risks in individuals 65 years and older with a chronic disease.

Regarding the subjective well-being assessment area from HRQoL subdimensions (pain/discomfort and anxiety/depression), most of the participants in this study showed mild pain/discomfort and mild anxiety/depression. There were significant differences in subjective well-being variables in moderate and high levels of physical activity compared to low levels of physical activity. In accordance with many studies, in our study, physical activity has been found to have positive effects on depression and pain in individuals aged 65 and above $[3,34,39]$.

\section{CONCLUSIONS}

It was concluded that high and moderate physical activity levels have a great positive relationship with HRQoL in individuals 65 years and older with a chronic disease and positively affect HRQoL. It should be emphasized and suggested that physical activity is the driving force behind the positive effects of physical activity on HRQoL in order to develop an active lifestyle habit especially in individuals aged 65 and over with a chronic disease. Therefore, adopting a physically active lifestyle may contribute to better health and HRQoL among the elderly.

\section{ACKNOWLEDGEMENTS}

The authors would like to thank all middle-aged and older adult people who participated in this study.

\section{REFERENCES}

[1] Vagetti GC, Barbosa Filho VC, Moreira NB, Oliveira V, Mazzardo O, Campos Wd. Association between physical activity and quality of life in the elderly: a systematic review, 2000-2012. Rev Bras Psiquiatr. 2014;36(1):76-88. https://doi.org/10.1590/1516-4446-2012-0895

[2] Anderson E, Durstine J.L. Physical activity, exercise, and chronic diseases: A brief review. Sport Med Health Sci. 2019;1:3-10. https://doi.org/10.1016/j.smhs.2019.08.006

[3] Halaweh H, Willen C, Grimby-Ekman A, Svantesson U. Physical activity and health-related quality of lifeamong community dwelling elderly. J Clin Med Res. 2015;7(11):845-52. https://doi.org/10.14740/ jocmr2307w

[4] Hajian Tilaki K, Hajian Tilaki A. Are gender differences in health related quality of life attributable to sociodemographic characteristics and chronic disease conditions in elderly people? Int J Prevent Med. 2017;8(95):1-5. DOI:10.4103/ijpvm.IJPVM_197_16

[5] Kadariya S, Gautam R and Aro A.R. Physical activity, mental health, and wellbeing among older adults in South and Southeast Asia: A Scoping Review. BioMed Res Int. 2019:1-12. https://doi. org/10.1155/2019/6752182

[6] Lear SA, Hu W, Rangarajan S, et al. The effect of physical activity on mortality and cardiovascular disease in 130000 people from 17 high-income, middle-income, and low-income countries: the PURE study. Lancet. 2017;390(10113):2643-2654. https://doi.org/10.1016/S0140-6736(17)31634-3

[7] Pedersen BK, Saltin B. Exercise as medicine - evidence for prescribing exercise as therapy in 26 different chronic diseases. Scand J Med Sci Sport. 2015;25(Suppl 3):1-72. https://doi.org/10.1111/ sms. 12581

[8] Balboa-Castillo T, Leon-Munoz LM, Graciani A, Rodríguez-Artalejo F, Guallar-Castillón P. A longitudinal association of physical activity and sedentary behavior during leisure time with health-related quality of life in community-dwelling older adults. Health Qual Life Outcomes 2011;9:47. https:// doi.org/10.1186/1477-7525-9-47 
[9] Katzmarzyk PT, Lear SA. Physical activity for obese individuals: A systematic review of effects on chronic disease risk factors. Obes Rev. 2012;13(2):95-105. https://doi.org/10.1111/j.1467789X.2011.00933.x

[10] Fogelholm M. Physical activity, fitness and fatness: relations to mortality, morbidity and disease risk factors. A systematic review. Obes Rev. 2010;11(3):202-221. https://doi.org/10.1111/j.1467789X.2009.00653.x

[11] Anderson L, Oldridge N, Thompson DR, et al. Exercise-based cardiac rehabilitation for coronary heart disease: cochrane systematic review and meta-analysis. J Am Coll Cardiol. 2016;67(1):1-12. https://doi.org/10.1016/j.jacc.2015.10.044

[12] Abdelbasset WK, Nambi G. Relationship between physical activity and health-related quality of life in elderly people: A cross-sectional study. Sanamed. 2017;12:87-92. https://doi.org/10.24125/ sanamed.v12i2.186

[13] Simpson RJ, Campbell JP, Gleeson M, et al. Can exercise affect immune function to increase susceptibility to infection? Exerc Immunol Rev. 2020;26:8-22.

[14] Duggal NA, Niemiro G, Harridge SDR, Simpson RJ, Lord JM. Can physical activity ameliorate immunosenescence and thereby reduce age-related multi-morbidity? Nat Rev Immunol. 2019;19: 563-572. https://doi.org/10.1038/s41577-019-0177-9

[15] Gleeson M, Bishop NC, Stensel DJ, Lindley MR, Mastana SS, Nimmo MA. The anti-inflammatory effects of exercise: mechanisms and implications for the prevention and treatment of disease. Nat Rev Immunol. 2011;11:607-615. https://doi.org/10.1038/nri3041.

[16] Hojman P, Gehl J, Christensen JF, Pedersen BK. Molecular Mechanisms linking exercise to cancer prevention and treatment. Cell Metabol. 2018;27:10-21, 2018. https://doi.org/10.1016/j. cmet.2017.09.015

[17] Simpson RJ, Kunz H, Agha N, Graff R. Exercise and the regulation of immune functions. Prog Mol Biol Transl Sci. 2015;135:355-380. https://doi.org/10.1016/bs.pmbts.2015.08.001

[18] Walsh NP, Gleeson M, Shephard RJ, et al. Position statement. Part one: Immune function and exercise. Exerc Immunol Rev. 2011;17:6-63.

[19] Fayers PM, Machin D. Quality of life: the assessment, analysis, and reporting of patient-reported outcomes. 3rd ed. Chichester, West Sussex, England: Wiley Blackwell; 2016. 651 p. https://doi. org/10.1002/9781118758991

[20] Bize R, Johnson JA, Plotnikoff RC. Physical activity level and health-related quality of life in the general adult population: A systematic review. Prev Med. 2007;45(6):401-15. https://doi.org/10.1016/j ypmed.2007.07.017

[21] Rejeski WJ, Mihalko SL. Physical activity and quality of life in older adults. J Gerontol A Biol Sci Med Sci. 2001; 56 Spec No 2:23-35. https://doi.org/10.1093/gerona/56.suppl_2.23

[22] Pucci GC, Rech CR, Fermino RC, Reis RS. Association between physical activity and quality of life in adults. Rev Saude Publica. 2012;46(1):166-79. https://doi.org/10.1590/S0034-89102012000100021

[23] Ortlieb S, Gorzelniak L, Nowak D, et al. Associations between multiple accelerometry-assessed physical activity parameters and selected health outcomes in elderly people-results from the KORAAge Study. PLoS One. 2014;9(11):e111206. https://doi.org/10.1371/journal.pone.0111206

[24] Svantesson U, Jones J, Wolbert K, Alricsson M. Impact of physical activity on the self-perceived quality of life in non-frail older adults. J Clin Med Res. 2015;7(8):585-93. https://doi.org/10.14740/ jocmr2021w

[25] Choi M, Prieto-Merino D, Dale C, et al. Effect of changes in moderate or vigorous physical activity on changes in health related quality of life ofelderly British women over seven years. Qual Life Res. 2013;22(8):2011-20. https://doi.org/10.1007/s11136-012-0332-2

[26] Katz S, Ford AB, Moskowitz RW, Jackson BA, Jaffe MW. Studies of illness in the aged. The index of adl: a standardized measure of biological and psychosocial function. JAMA. 1963;185:914-919. https://doi.org/10.1001/jama.1963.03060120024016

[27] Brorsson B, Asberg KH. Katz index of independence in ADL. Reliability and validity in short-term care. Scand J Rehabil Med. 1984;16(3):125-132. PMID: 6494836

[28] World Health Organization. Global recommendations on physical activity for health. Geneva, Switzerland: WHO; 2010.

[29] Aburuz S, Bulatova N, Twalbeh M, Gazawi M. The validity and reliability of the Arabic version of the EQ-5D: A study from Jordan. Ann Saudi Med. 2009;29:304-8. https://doi.org/10.4103/02564947.55313

[30] Machon M, Larranga I, Dorronsoro M, Vrotsou K, Vergara I. Health-related quality of life and associated factors in functionally independent older people. BMC Geriatrics. 2017;17:19. https:// doi.org/10.1186/s12877-016-0410-3

[31] Kowalski K, Rhodes R, Naylor PJ, Tuokko H, MacDonald S. Direct and indirect measurement of physical activity in older adults: a systematic review of the literature. Int J Behav Nutr Phys Act. 2012;9:148. https://doi.org/10.1186/1479-5868-9-148

[32] Pedersen BK, Saltin B. Evidence for prescribing exercise as therapy in chronic disease. Scand J Med Sci Sports. 2006;16 (Suppl 1):3-63. https://doi.org/10.1111/j.1600-0838.2006.00520.x

[33] Acree LS, Longfors J, Fjeldstad AS, et al. Physical activity is related to quality of life in older adults. Health Qual Life Outcomes. 2006;4:37. https://doi.org/10.1186/1477-7525-4-37

[34] Beitz R and Doren M. Physical activity and postmenopausal health. J Br Menopause Soc. 2004; 10:70-4. https://doi.org/10.1258/136218004774202382

[35] Peter D. Hart. Physical activity and health-related quality of life in rural adults with chronic disease. Am J Med Sci Med. 2017;5(3):62-66. https://doi.org/10.12691/ajmsm-5-3-5 
Baltic Journal of Health and Physical Activity 2020; 12 (3): 103-113

Journal of Gdansk University of Physical Education and Sport

e-ISSN 2080-9999

[36] Jahangiry L, Montazeri A, Najafi M, Yaseri M, Farhangi MA. An interactive web-based intervention on nutritional status, physical activity and health-related quality of life in patient with metabolic syndrome: a randomized-controlled trial (The Red Ruby Study). Nutrition \& Diabetes. 2017 Jan 1; 7(1):e240. https://doi.org/10.1038/nutd.2016.35

[37] Atalay OT and Cavlak U. The impact of unsupervised regular walking on health: A sample of Turkish middle-aged and older adults. Eur Rev Aging Phys Act. 2012;9:71-9. https://doi.org/10.1007/s11556011-0083-z

[38] Holland R, Smith RD, Harvey I, Swift L, Lenaghan E. Assessing quality of life in the elderly: A direct comparison of the EQ-5D and AQoL. Health Econ. 2004;13:793-805. https://doi.org/10.1002/hec.858

[39] Abdelbasset WK, Alsubaie SF, Tantawy SA, Abo Elyazed TI, Ahmed A, Elshehawy AA. A cross-sectional study on the correlation between physical activity levels and healthrelated quality of life in communitydwelling middle-aged and older adults. 2019. https://doi.org/10.1097/MD.0000000000014895 